\title{
Investigation into deep hole drilling of austenitic steel with advanced tool solutions
}

\author{
Nils Felinks ${ }^{1}$ - Timo Rinschede ${ }^{1} \cdot$ Dirk Biermann $^{1} \cdot$ Dominic Stangier $^{2} \cdot$ Wolfgang Tillmann $^{2} \cdot$ Moritz Fuß $^{3}$. \\ Hendrik Abrahams ${ }^{4}$
}

Received: 25 May 2021 / Accepted: 31 August 2021 / Published online: 13 September 2021

(C) The Author(s) 2021

\begin{abstract}
Deep hole drilling processes for high-alloyed materials are characterised by worn guide pads and chatter vibrations. In order to increase feed rates, process stability and bore quality in STS deep hole drilling, various investigations were carried out with adjustments to the tool. First, a new process chain for the production of tribologically optimised guide pads and their effects on the guide pad shape is described in detail. The results of these studies show that the shape change in the area of the axial run-in chamfer through a micro finishing process leads to a better bore hole quality. Furthermore, the influence of guide pad coating and cooling lubricant on the deep hole drilling process was investigated. In addition, the machining of the austenitic steel AISI 304 is analysed by using a conventional steel boring bar and an innovative carbon fibre reinforced plastic (CFRP)-boring bar. While the conventional drill tube oscillates with different eigenfrequencies, the CFRP-boring bar damps chatter vibrations of the drill head and stabilises the process. Even at higher feed rates up to $f=0.3 \mathrm{~mm}$, it is possible to machine austenitic, difficult-to-cut-materials with significantly reduced vibrations.
\end{abstract}

Keywords STS deep hole drilling · Guide pads · Cutting tool coating $\cdot$ CFRP-boring bar $\cdot$ Chatter vibrations · AISI 304

\section{Introduction}

Modern machining technology aspires the combination of economical productivity and increased quality. The technology of deep hole drilling enables the possibility to produce deep bore holes, which is in response to these challenges. Compared to the competing drilling processes, conventional deep hole drilling with asymmetrical tool structure is effective in achieving very large length-to-diameter (1/D) ratios,

Nils Felinks

nils.felinks@tu-dortmund.de

1 Institute of Machining Technology (ISF), TU Dortmund University, Baroper Str. 303, D-44227 Dortmund, Germany

2 Institute of Materials Engineering (LWT), TU Dortmund University, Leonhard-Euler-Str. 2, D-44227 Dortmund, Germany

3 Beratende Gesellschaft für Tiefbohr- und Zerspanungstechnik (BGTB) GmbH, Dorstfelder Hellweg 60,

D-44149 Dortmund, Germany

4 Märkisches Werk GmbH, Haus Heide 21, D-58553 Halver, Germany especially used for deep bore holes with a ratio larger than 10 [1]. During deep hole drilling processes, the bore hole wall is formed by the supporting guide pads, whereby bore holes with very low surface roughness depths $R z$ can be produced [2]. During the machining process, high mechanical loads stress the guide pads, which lead to an extensive wear of these components [3]. Depending on the materials to be machined, such as austenitic steels, these loads increase and exceed the initial state multiple [4]. These steel grades in particular cause high abrasive and adhesive tool wear [5]. Previous research at the Institute of Machining Technology has already focused on the wear of guide pads in single tube system (STS) deep hole drilling of austenitic steels $[4,6]$. Special attention was paid to the shape of diamond-like carbon (DLC)-coated guide pads, on tool wear behaviour and on quality of the drilled bore holes. Furthermore, ta-C coated guide pads have been successfully applied to increase the tool life and bore hole quality $[6,7]$. Due to its high hardness and low coefficient of friction, ta-C coatings proved to be a good solution to compensate the process-related high force and wear stress of the guide pads under lubricated conditions [8]. In this study, deep drilling oil was used as usual in STS drilling. 


\subsection{Increasing bore quality and tool life in single-lip drilling of austenitic steels}

Using twist drills for drilling austenitic steels, intense mechanical loads and tool wear at the outer corner occur [9]. Alternatively, single-lip drills are used in industrial applications as tools for deep hole drilling austenitic steel. The implementations of these drilling processes are performed on deep hole drilling machines as well as on machining centres, which both use emulsions as coolants [10]. Industrial companies using central lubrication systems mostly run their deep hole drilling machines with emulsion lubricant [11]. Due to higher prioritisation on the cooling effect over the lubricating effect, water-miscible lubricants are primarily used. In deep hole drilling, a minor part of the heat is transferred to the coolant lubricant [1]. Moreover, in deep hole drilling, the coolant's lubricating effect on the guide pads has a significant influence on the wear and thus on the bore hole quality [7]. Firstly, Biermann et al. have studied the effects of microfinished guide pads on bore surface quality in SLS drilling. They found out that a friction reducing coating (e.g. ta-C) is appropriate to reduce abrasive wear effects $[4,6]$. In order to evaluate the guide pad's characteristics and estimate the cutting performance, the analysis of microstructures and mechanical properties was performed [12]. In experimental tests, the tribological qualities were determined in the form of tool wear, workpiece surface roughness and mechanical loading [13].

Consequently, the results for single-lip deep hole drilling of the austenitic steel AISI 304 with tribologically optimised guide pads under variation of the coolant are presented and discussed in the first part of the article.

\subsection{Depression of chatter vibrations in STS drilling}

Another characteristic of deep hole drilling processes is the vibration tendency of the tool. Torsional and bending vibrations often accompany the processes. Bending vibrations are the result of deficient alignments of the machine components or insufficient support of the boring bar used. To minimise vibrations, there are active damping systems in machine tools, which accelerate a reaction force on the components [14]. Also, dynamic vibration absorbers in boring bars for turning and guide pad structure in deep hole drilling are appropriate to reduce chatter in tools $[15,16]$. Furthermore, rotational speed is a decisive variable, as this can trigger a resonance of the machine tool, which can cause bending vibrations. In contrast, torsional vibrations are primarily influenced by the feed rate and the workpiece material [17]. Therefore, high strength materials effect chatter vibrations. Moreover, tough materials with high adhesion tendency lead to a stick-slip effect at the guide pads, which can also have an influence on tool vibration [18]. For this reason, STS deep hole drilling processes of difficult-to-cut materials are accompanied by chatter vibrations, independent from boring bar length and cutting parameters. In order to reach an acceptable tool life, it is necessary to reduce the feed rate and to use a passive damping system [18].

In the second part of the article, the potential of a new type of boring bar made of carbon fibre reinforced plastic (CFRP) is shown and analysed as a solution for reducing process vibrations and improving feed rates.

\section{Guide pad wear during deep hole drilling of austenitic steel}

\subsection{Experimental setup and method}

The experiments were carried out on a deep drilling machining centre, type Ixion TLF 1004 and on a Heller FT4000 fiveaxis machining centre. Isocut $\mathrm{T} 404$ deep drilling oil from Petrofer Chemie H.R. Fischer GmbH \& Co. KG is used on the deep drilling machining centre. With a viscosity of $\nu=$ $10.1 \mathrm{~mm}^{2} / \mathrm{s}$ (at $T=313 \mathrm{~K}$ ), it is known as low-viscosity drilling oil and has been specially developed for single-lip deep hole drilling of small diameters. For deep hole drilling tests with emulsion, the water-miscible concentrate Avantin 4409 from Carl Bechem $\mathrm{GmbH}$ was used in a volume ratio of $8 \%$ on the five-axis machining centre. Both coolants are designed for steel cutting and are alloyed with appropriate additives. Fig. 1a shows the used deep hole drilling tool with a diameter of $d_{\text {tool }}=13 \mathrm{~mm}$. The wear elements indexable insert and guide pads can be replaced on this tool. The guide pads used are made of carbide grade P20 and are differently coated with TiN, TiAlN and ta-c (tetra amorphous carbon) in order to increase tool life [19]. Additionally, specific pre-treatments were applied. Fig. $1 \mathrm{~b}$ shows the three differently coated guide pads. Conventionally, the guide pads undergo a polishing process before and after the coating. In order to optimise the shape of the uncoated guide pads, a micro finishing process was realised by a superfinish attachment of type Supfina 202. The micro finishing is characterised by an interaction of two overlaid relative movements. The typically finished surface structure is based on the described specific process kinematic: the rotating shaft on the one hand and the oscillating press roll on the other hand. In this special case, a shaft is designed with grooves for fixing the guide pads as shown in Fig. 1c. Furthermore Fig. 1d shows the contact situation between the flexible pressure roller and a guide pad. With regard to the high hardness and wear resistance of the guide pad's coatings, diamond was used as cutting material [7].

In order to analyse the cooling lubricant's as well as the coatings effects on machinability of AISI 304 austenitic steel, various methods are common in scientific context. $\mathrm{Li}$ et al. used a Spike-T system to evaluate mechanical tool loads in context of tool wear experiments. Further wear signs were 
Fig. 1 (a) Used deep drilling tool; (b) types of the coated guide pads; (c) setup of the finishing process; (d) tool contact situation during finishing process
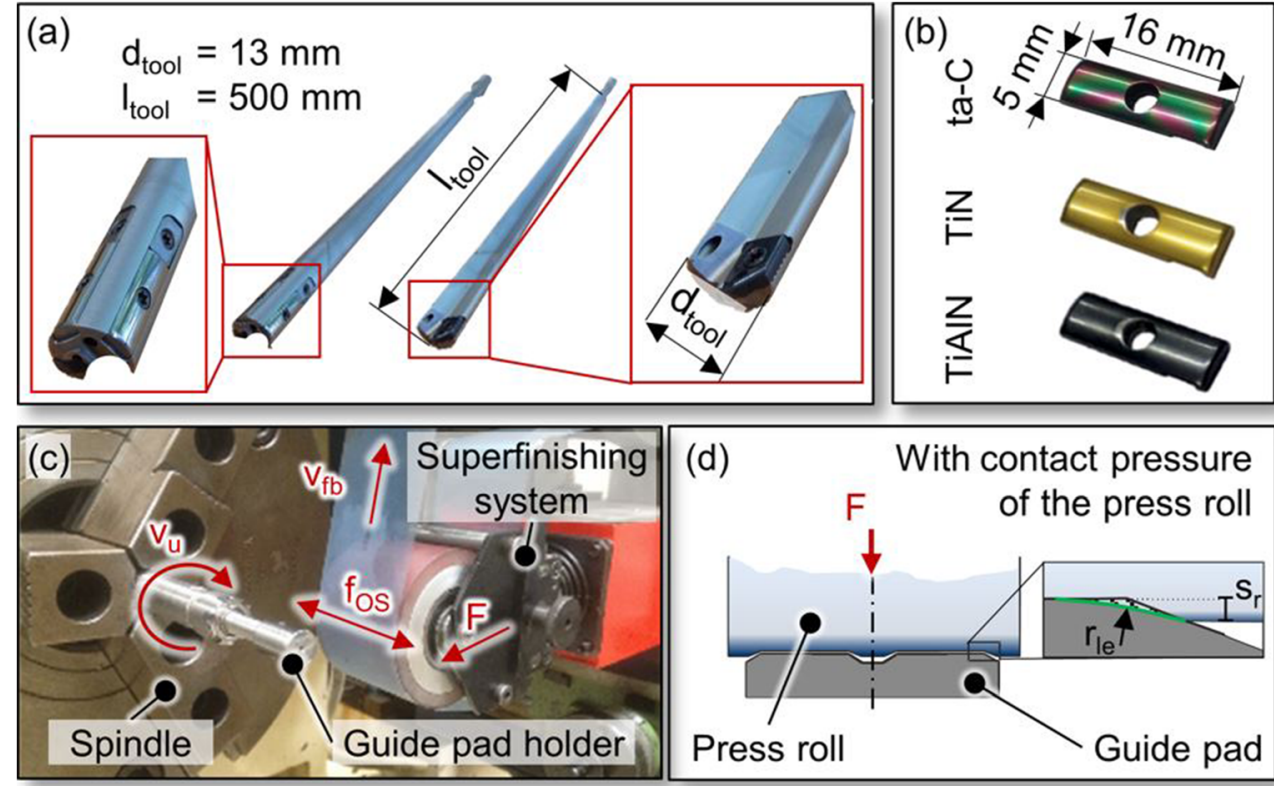

taken by a light microscope, which was integrated to the machining tool and process [20]. Arif et al. applied a drilling dynamometer type Kistler 9125 in their study to provide high quality measurement of mechanical tool loads. They showed in their research, that using piezoelectric measuring systems are applicable to determine cutting force [21]. In this study, wear signs were analysed by a light microscope type Keyence VHX 5000 in the field, in comparison to Martinho et al. who used SEM imaging ex situ for detailed, microscopic analysis of cutting performance [22]. In order to compare macroscopic as well as microscopic wear signs between lubrication types, a light microscope was used in this study.

Nickel et al. used a testing method, which based on Barkhausen noise in context of single-lip drilling, nondestructive methods and surface integrity [23]. When lubrication and coating qualities are in focus, tactile measuring of surface quality is appropriate. In the performed experimental investigations, bore holes were analysed by a MahrSurf XR20 device. The methodology of this study is represented in Fig. 2.

\subsection{Analysis of the micro finished guide pads and the subsequent coating process}

Fig. 3a shows the achieved surface quality of the tribologically optimised guide pads. During the finishing process, the shaft rotated with a rotational speed of up to $v_{\mathrm{p}}=25 \mathrm{~m} / \mathrm{min}$, while the press roll oscillated with a frequency of $f_{\text {os }}=20 \mathrm{~Hz}$ ( shown in Fig. 3b). In addition to the choice of the specific cutting parameters, there are several possibilities to influence the tool and process characteristics. On the one hand, the hardness of the press roll can be varied. On the other hand, the surface quality can be improved by using different grain sizes in subsequent process steps. These variations and their influences have been investigated in different studies [6, 7]. A very short process was designed for these guide pad sizes. During the process time of approx. $t=30 \mathrm{~s}$, a 90 shore pressure roller and

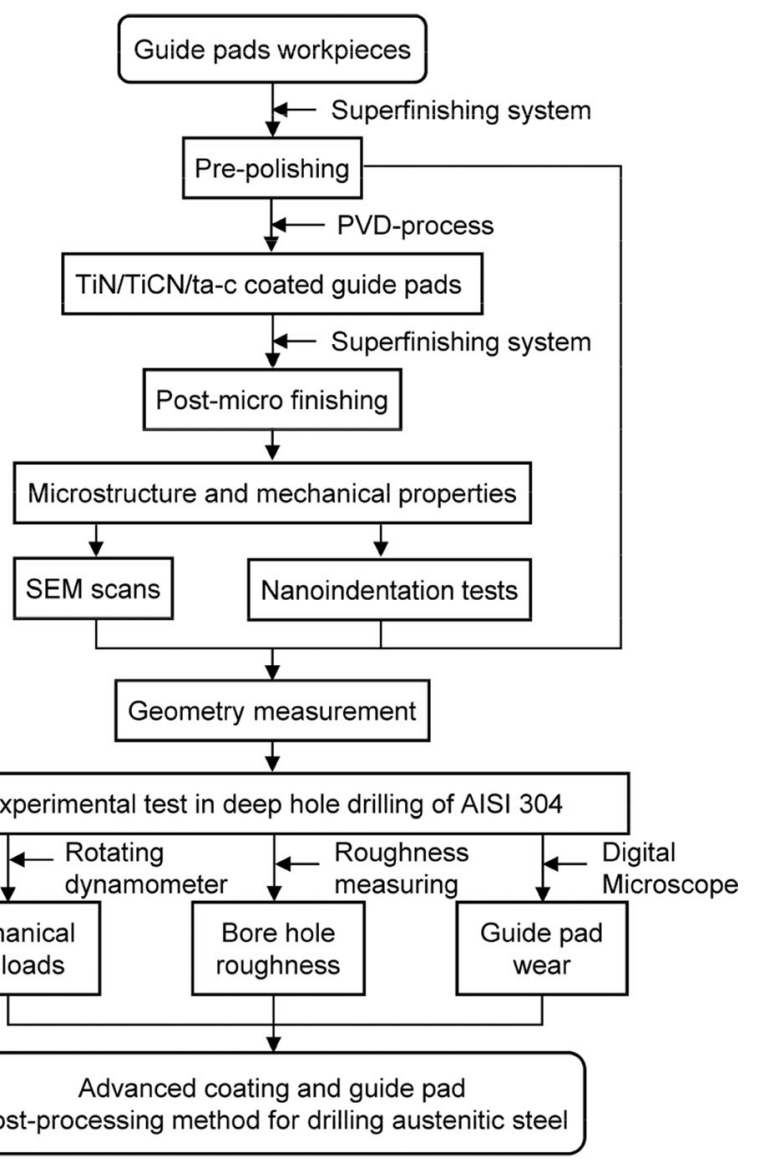

Fig. 2 Methods of guide pad post-processing and experimental test 
Fig. 3 (a) Finishing process sequence and results; (b) finish parameters; (c) detailed view of the guide pad shape

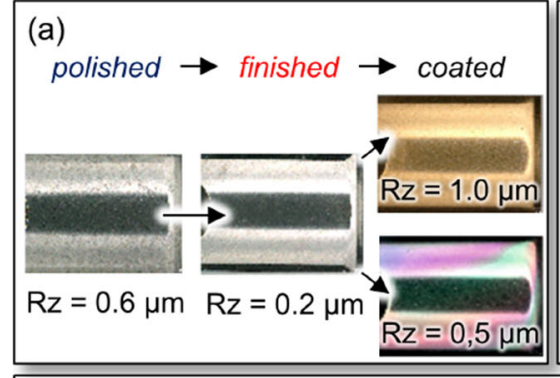

(b) Oscillation frequency: $f_{\text {os }}=20 \mathrm{~Hz}$

Workpiece rotation speed: $\mathrm{v}_{\mathrm{u}}=25 \mathrm{~m} / \mathrm{min}$

Pressing force: $\mathrm{F}=60 \mathrm{~N}$

Belt-feed speed: $\mathrm{v}_{\mathrm{fb}}=20 \mathrm{~mm} / \mathrm{min}$

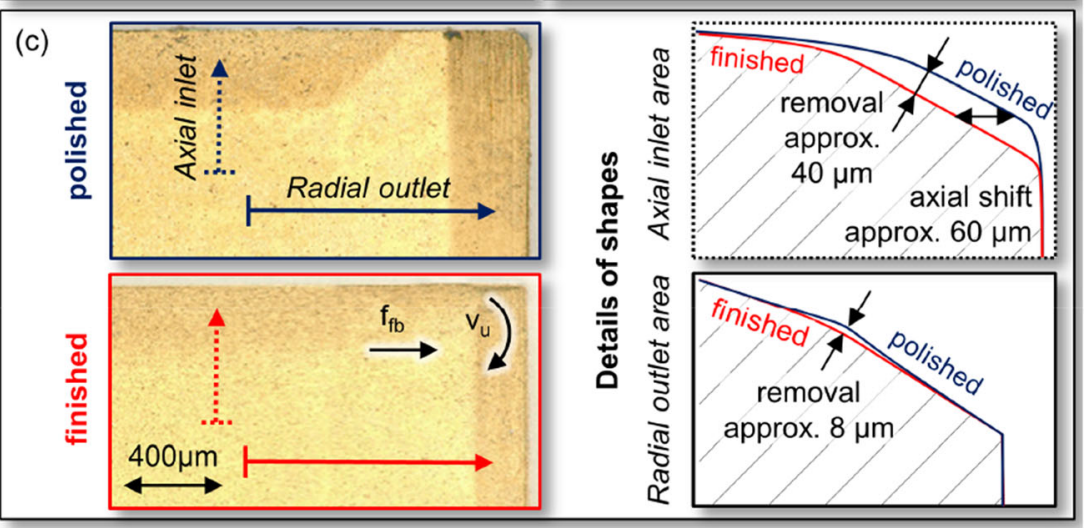

a belt with $9-\mu \mathrm{m}$ grain size under a pressure force of approx. $F$ $=60 \mathrm{~N}$ were used.

The finishing not only improves the surface quality but also changes the shape of the guide pad [6]. In the detailed illustration of the guide pad corner, Fig. $3 \mathrm{c}$ shows that the edges after polishing were rounded by the finishing process. As shown in Fig. 1d, the pressure roll wraps around the guide pad in the area of the run-in chamfer elastically, which results in this rounding. A measuring microscope type Alicona InfiniteFocus G5 was used to measure the profiles in the radial inlet/outlet area and in the axial inlet/outlet area. The material removal in the radial inlet and outlet area is relatively low (approx. $8 \mu \mathrm{m}$ ), but the transition to the ground chamfer is completely rounded. The material removal in the axial inlet area and the resulting rounding is significantly higher. The oscillating movement of the ductile pressure roll is perpendicular to this edge, which significantly increases the removal rate. This removal causes the axial contact point of a profiled guide pad to be shifted backwards by approx. $60 \mu \mathrm{m}$ from the tip of the cutting edge compared to a conventional guide pad. These changes the equilibrium of forces at the tool head to a small extent.

To improve the tribological properties of the cemented carbide guide pads, three PVD coatings were applied and investigated [24, 25]. On the one side, conventional Ti-based nitride coatings such as TiN and TiAlN were selected due to their high wear resistance and well-known tribological properties [26]. On the other side, a ta-C coating from the group of DLC coatings offers a low friction for sliding against steel counter bodies and possesses a high hardness at the same time
[27]. The cryogenic broken cross-section fracture images taken by SEM (type JEOL FE JSEM 7001, Japan) of the coated guide pads are illustrated in Fig. 4. The TiN coating shows a thickness of $1.69 \mu \mathrm{m}$, whereas the TiAlN and ta-C coating show a smaller thickness of $0.68 \mu \mathrm{m}$ and $0.52 \mu \mathrm{m}$, respectively. However, Ti-based nitrides have a surface roughness depth of $R z \approx 1 \mu \mathrm{m}$, whereas the roughness profile of the ta-C coating has values of $R z=0.5 \mu \mathrm{m}$. These inherent properties of the coating can be explained by the different phase composition of the coatings. Amorphous coatings in comparison to crystalline thin films have a lower roughness profile. Additionally, the high residual stresses of ta-C coatings result in the increased hardness and low coating thickness.

The mechanical properties of the coatings were investigated by a nanoindenter G200 (Agilent Technologies, USA) according to the method suggested by Oliver and Pharr [28-30]. The hardness of the coating showed almost similar mechanical properties for the TiN and TiAlN coating with hardness values above $20 \mathrm{GPa}$. In contrast to this, the hardness of ta-C coating was determined to be approx. $40 \mathrm{GPa}$. The difference of the mechanical properties is a result of the phase composition and different types of bondings. Especially, the covalent bonding of carbon and the hybridization of the orbitals (ratio of $\mathrm{sp}^{3} / \mathrm{sp}^{2}$ ) lead to high hardness [31].

With respect to the interactions of the coatings with the cemented carbide substrate, the residual stresses of the coated WC-Co substrate were measured by X-ray diffraction as it is presented in a former study of the authors [32]. It is noticeable that for all substrates a slightly anisotropic compressive stress state was found in the WC phase. The difference in the 
Fig. 4 (a) SEM pictures of the cross section and topography of the PVD coatings; (b) hardness of the coating; (c) residual stresses in the substrate
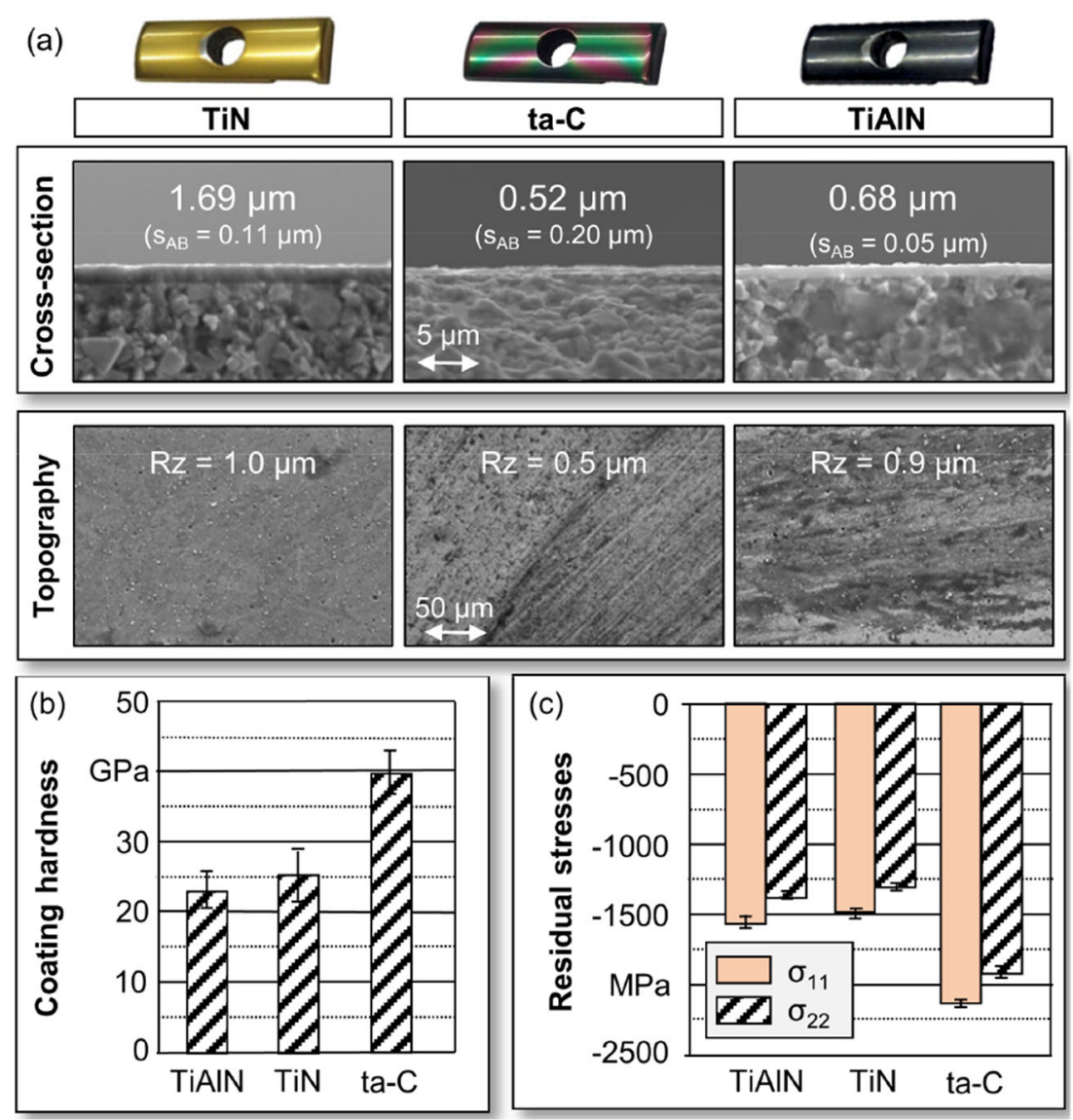

orientation of the stresses is caused by the kinematics of the finish pre-treatment of the guide pads prior to the deposition process. The highest compressive stresses were determined for the substrate of the ta-C coating ( $\sigma=-2034 \pm 34 \mathrm{MPa})$. This directly correlates with the mechanical properties determined by nanoindentation and the interaction between coating and substrate. Summarising the presented properties, ta-C coatings are a highly promising opportunity for the field of deep hole drilling.

\subsection{Results of experimental drilling tests}

Fig. 5 shows that the guide pads experienced different wear depending on their previous preparation and the coolant used. The polished guide pads, with an axial chamfer transition to the support area, show linear contact marks independent of the variation of the lubricant. The finished guide pads, on the other hand, show a more pronounced contact area in the direction of rotation. The rounding in the area of the run-in chamfer implies the fact that a larger part of the workpiece material in the finished pads comes between the support area and the bore wall $[2,33]$. The high tendency of the austenitic steel to strain harden leads to significant material adhesion to the guide pad and has a significant influence on the bore hole surface quality.
According to this, the achievable bore hole qualities under the use of emulsion are lower than with deep drilling oil. The oil improves the contact conditions between the friction partners in the area of the axial inlet, which reduces the friction moment. The frictional heat generated at this point is reduced at the same time. The tendency of adhesive wear increases with higher temperature, which is why the wear under oil is lower at this point. The rear support area between the bore wall and the guide pad is sufficiently flushed by the coolant and thus well cooled. The higher cooling capacity of the emulsion has a positive effect on wear development. The more pronounced tendency to adhesion and the greater frictional torque on the guide pads and in the area of the chip formation zone lead to a higher mechanical tool load during the process when using emulsion.

Fig. 6 shows the results for guide pad wear of austenitic steel with variation of the coating. In the industrial implementation, both emulsion and deep drilling oil are used. Therefore, this influence has also been investigated. The process execution with deep drilling oil produces better drilling qualities compared with the use of emulsion. The low lubrication effect in the axial inlet area clearly promotes the adhesion tendency, which is why there is a stronger development of wear than with the use of oil. Compared to the other two coatings, the ta$\mathrm{C}$ coating has an improved friction behaviour and a higher 
Fig. 5 Results on the performance of conventional and finish-machined TiN-coated guide pads in deep drilling of austenitic steel

\begin{tabular}{|llll|}
\hline Material: & AISI 304 & Feed rate: & $f=0.08 \mathrm{~mm}$ \\
Tool: & SLD $\varnothing=13 \mathrm{~mm}$ & Cutting speed: & $\mathrm{v}_{\mathrm{c}}=70 \mathrm{~m} / \mathrm{min}$ \\
GP-Coating: & TiN & Drilling length: & $\mathrm{I}_{\mathrm{f}}=5.2 \mathrm{~m}$ \\
Lubricant: & varied & Drilling depth: & $\mathrm{I}_{\mathrm{t}}=260 \mathrm{~mm}$ \\
\hline
\end{tabular}

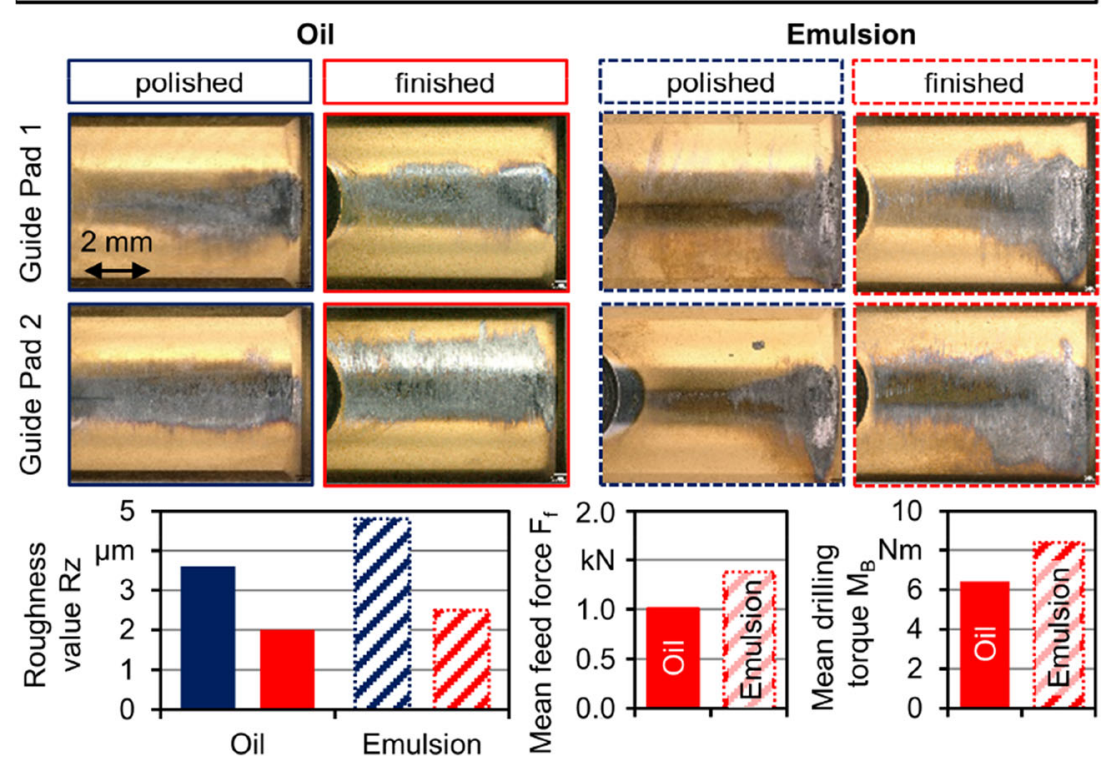

layer hardness. As a result, there is no wear in the rear part of the support area. This area has the last contact with the bore wall, which gives it a significant influence on the surface quality. The ta-C coating has a lower temperature resistance than titanium-based coatings, wherefore the advantage of high hardness and good friction properties in the front contact area is not given. The wear marks of the ta- $\mathrm{C}$ and TiN coating are comparable. During the tests with the titanium-based coated guide pads, a shrill whistle generated by vibrations was registered acoustically.

This acoustic perception is not given in the process with ta$\mathrm{C}$ coated guide pads. The reason for this is the lower tendency of adhesion between the coating and the workpiece material. The TiAlN coating shows the highest wear irrespective of the cooling lubricant used and consequently produces the lowest bore hole quality. The wear patterns show clear defects on the
Fig. 6 Results for deep drilling of austenitic steel under variation of guide pad coating and cooling lubricant

\begin{tabular}{llll}
\hline Material: & AISI 304 & Feed rate: & $f=0.08 \mathrm{~mm}$ \\
Tool: & SLD $\varnothing=13 \mathrm{~mm}$ & Cutting speed: & $\mathrm{v}_{\mathrm{c}}=70 \mathrm{~m} / \mathrm{min}$ \\
GP-Coating: & varied & Drilling length: & $\mathrm{I}_{\mathrm{f}}=5.2 \mathrm{~m}$ \\
Lubricant: & varied & Drilling depth: & $\mathrm{I}_{\mathrm{t}}=260 \mathrm{~mm}$ \\
\hline
\end{tabular}

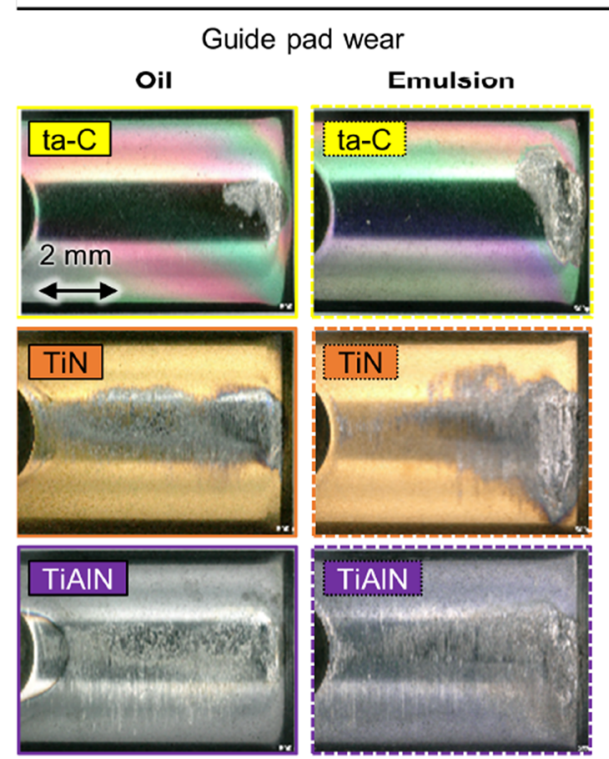

Mean surface roughness depth $\mathrm{Rz}$
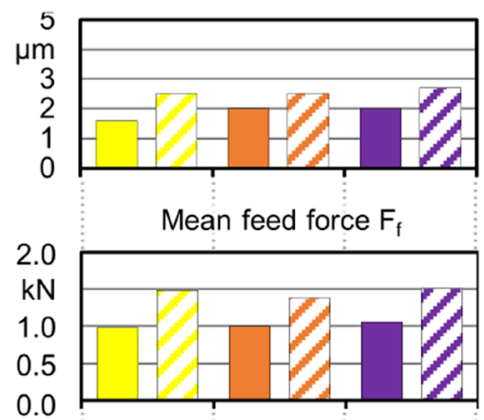

0.0

Mean drilling torque $M_{B}$

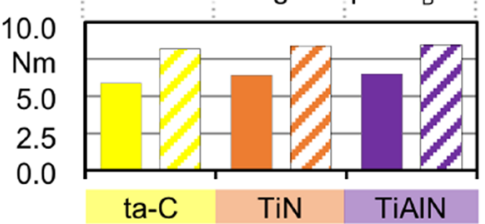


supporting surface. At these points, strong adhesion of the workpiece material and the coating has occurred, whereby the coating has been completely removed from the carbide substrate.

After a single occurrence, this process takes place repeatedly in the following, so that a delamination occurs over an increasing drilling path. During deep drilling, the mechanical tool load changes from austenitic steel with oil to emulsion by approx. $43 \%$ with regard to the feed force $F_{\mathrm{z}}$ and by approx. $33 \%$ with regard to the drilling torque $\mathrm{M}_{\mathrm{B}}$.

\section{CFRP-boring bar with improved damping characteristic for STS deep hole drilling of austenitic steels}

\subsection{Experimental setup and method}

The investigations have been carried out on a STS deep hole drilling machine type Giana GGB 560 (see Fig. 7). This machine tool enables the machining of bore holes with a maximum diameter of $D=300 \mathrm{~mm}$ and a maximum drilling length of $l_{\mathrm{t}}=3000 \mathrm{~mm}$. A workpiece spindle and a tool spindle enable different process strategies with rotating tool as well as rotating workpiece. The presented experimental tests have been carried out with a rotating workpiece and a non-rotating tool. This strategy was essential to measure the mechanical loads on the boring bar with resistance strain gauges. Fig. 7 shows the machine tool and the arrangement of the stain gauges on the boring bar.

The measurement of the torsional moment was carried out with two strain gauges which were switched as a full bridge. The strain gauges have a linear design with a length of the measuring grid of $l_{\mathrm{mg}}=6 \mathrm{~mm}$ and a measuring resistance of $R$ $=120 \Omega$. The passive sensors are glued to the boring bars next to the clamping position.

Mechanical loads during the process lead to deformation of the measuring grid, which causes a change in the electric resistances. Chatter can be detected and analysed by dint of the Wheatstone bridge circuit with a measuring system. In order to increase process stability, cutting forces data were analysed by using NI DIADEM software. By digital filtering the signals and using fast-Fourier transformation, chatter vibrations in the form of oscillatory cutting forces were determined [34]. In this study, a drill head from tool manufacturer botek Präzisionsbohrtechnik GmbH with a diameter of $d=$ $60 \mathrm{~mm}$ was used. This tool is equipped with two cutting inserts and three guide pads. The guide pads were adapted to STS deep hole drilling of AISI 304 as mentioned in the
Fig. 7 (a) Machine tool Giana GGB 560; (b) formation of resistance strain gauge; (c) drill head; (d) CFRP-boring bar; (e) mechanical properties of the investigated materials
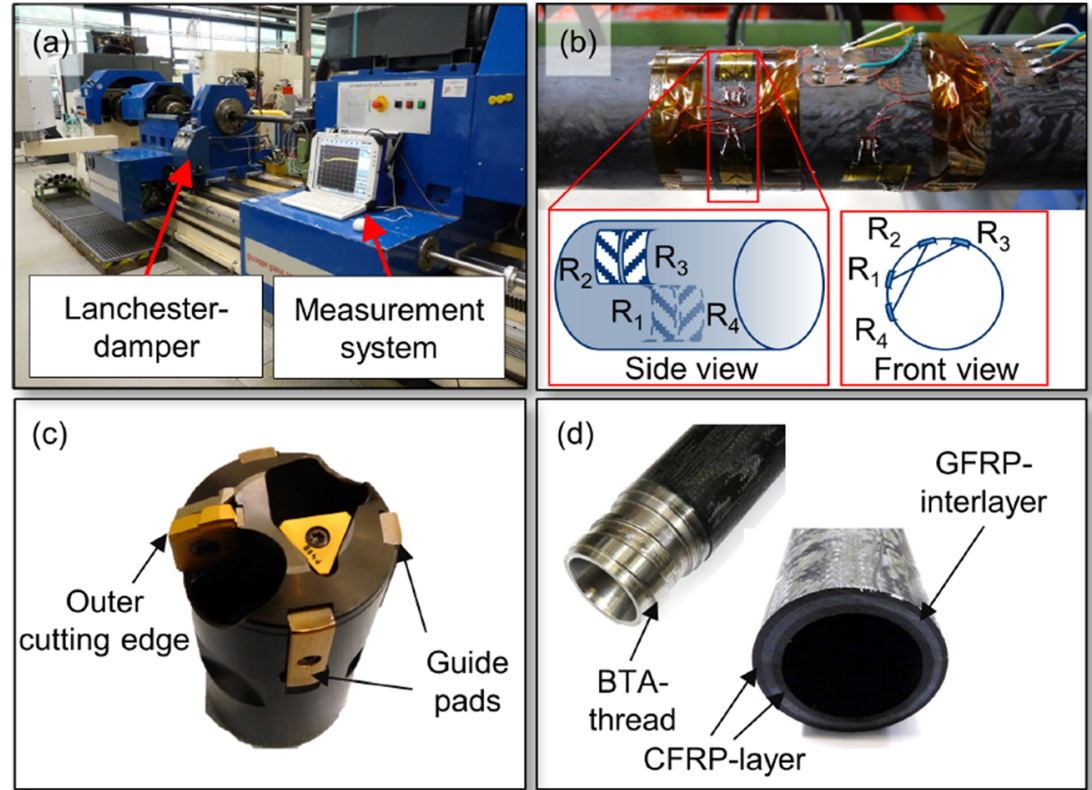

\begin{tabular}{|l|l|l|}
\hline \hline$(\mathrm{e})$ & AISI 1060 & AISI 304 \\
\hline Density $\rho$ & $7.83 \mathrm{~g} / \mathrm{cm}^{3}$ & $7.90 \mathrm{~g} / \mathrm{cm}^{3}$ \\
Yield Strength $\sigma_{\mathrm{y}}$ & $>340 \mathrm{MPa}$ & $337 \mathrm{MPa}$ \\
Tensile strength $\sigma_{\mathrm{u}}$ & $>670 \mathrm{MPa}$ & $627 \mathrm{MPa}$ \\
Heat treatment & normalized & solution annealed \\
Elongation $\varepsilon$ & $11 \%$ & $55 \%$ \\
Hardness $\mathrm{H}$ & $255 \mathrm{HB}$ & $187 \mathrm{HB}$ \\
\hline
\end{tabular}




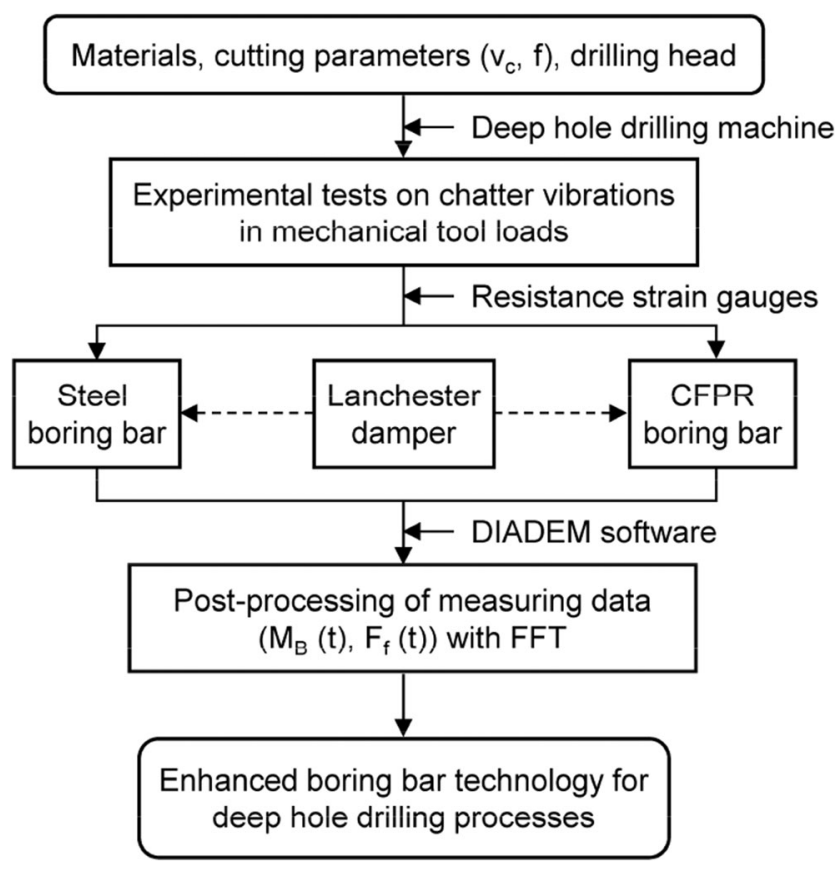

Fig. 8 Method of experimental test on passive damping methods for STS drilling

previous chapter. This includes a ta-C-coating and the pretreatment of the uncoated guide pads by micro finishing [6].

To analyse the process dynamics, two different boring bars were used. In reference tests, a conventional steel-boring bar
(AISI 4140) was installed, while an innovative CFRP-boring bar was developed for stabilising the deep drilling process. Fig. 7c, d shows the drill head and the CFRP-boring bar, which has been wound with $\pm 45^{\circ}$-fibre direction. Moreover, the wall thickness is about $s=7 \mathrm{~mm}$ consisting of an inner and outer CFRP winding (each with a thickness of $s=2 \mathrm{~mm}$ ) and a GFRP layer of $s=3 \mathrm{~mm}$. A thread is required to attach the drill head to the boring bar. For this reason, a metallic adapter, featuring a specific STS thread, was adhered into the bar over a length of $l=135 \mathrm{~mm}$. Both boring bars share the same dimensions with an inner diameter of $d_{\mathrm{i}}=37 \mathrm{~mm}$ and an outer diameter of $d_{\mathrm{o}}=51 \mathrm{~mm}$. The inner diameter of the adapter is about $d_{\text {Ad }}=27 \mathrm{~mm}$. The tests were carried out for two different workpiece materials. As a reference, the tempering steel AISI 1060 was used. Beyond that, the austenitic steel AISI 304, which belongs to the difficult-to-machine-materials, was drilled [35, 36]. Moreover, friction can lead to tribocorrosion [37]. For these reasons, STS deep hole drilling of AISI 304 is characterised by an adhesive guide pad wear as well as strong chatter vibrations [6]. Especially, the elongation of both materials differs significantly as the elongation of the austenitic steel is five times higher, compared to the elongation of the ferritic/perlitic steel. This leads to longer chip forms which can reduce the process reliability. In comparison to AISI 304, higher tensile strength and different grain structure of AISI 1060 in general cause small fragmented chips. Fig. 7e shows the mechanical properties of the investigated materials. The methodology of this study is summarised in Fig. 8.
Fig. 9 Influence of the feed rate on torsional vibrations when deep hole drilling AISI 1060

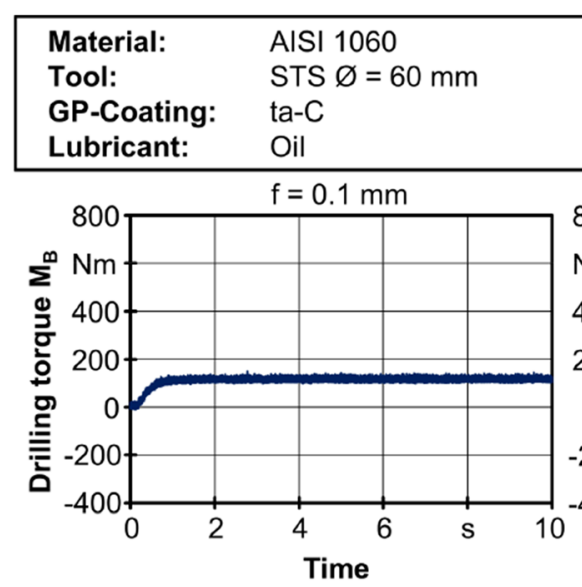

$\begin{array}{ll}\text { Feed rate: } & \text { varied } \\ \text { Cutting speed: } & \mathrm{v}_{\mathrm{c}}=80 \mathrm{~m} / \mathrm{min} \\ \text { Boring bar: } & \text { Steel } \\ \text { Damping: } & -\end{array}$

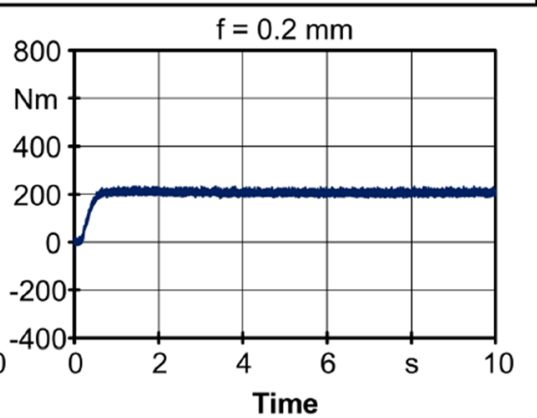

$\mathrm{f}=0.3 \mathrm{~mm}$
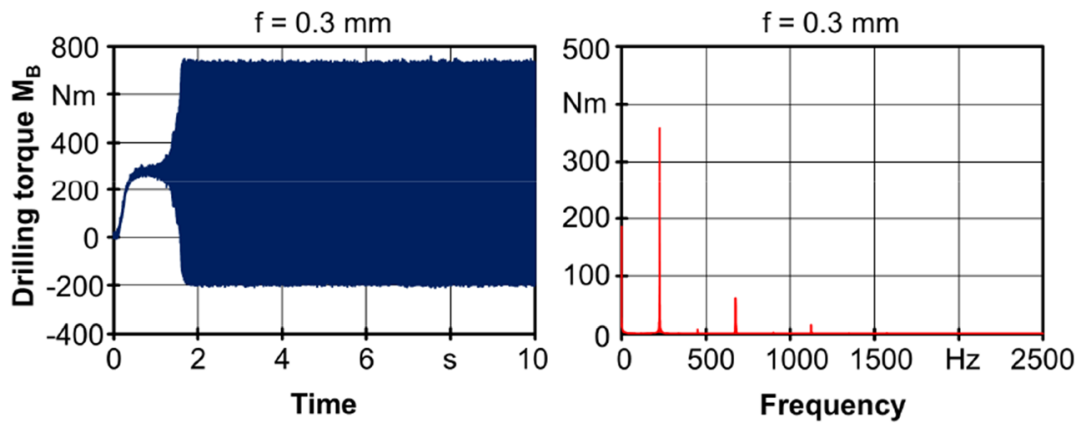
Fig. 10 Influence of feed rate on the torsional vibrations when machining AISI 304

\begin{tabular}{|llll|}
\hline Material: & AISI 304 & Feed rate: & varied \\
Tool: & STS $\varnothing=60 \mathrm{~mm}$ & Cutting speed: & $\mathrm{V}_{\mathrm{c}}=80 \mathrm{~m} / \mathrm{min}$ \\
GP-Coating: & ta-C & Boring bar: & Steel \\
Lubricant: & Oil & Damping: & - \\
\hline
\end{tabular}
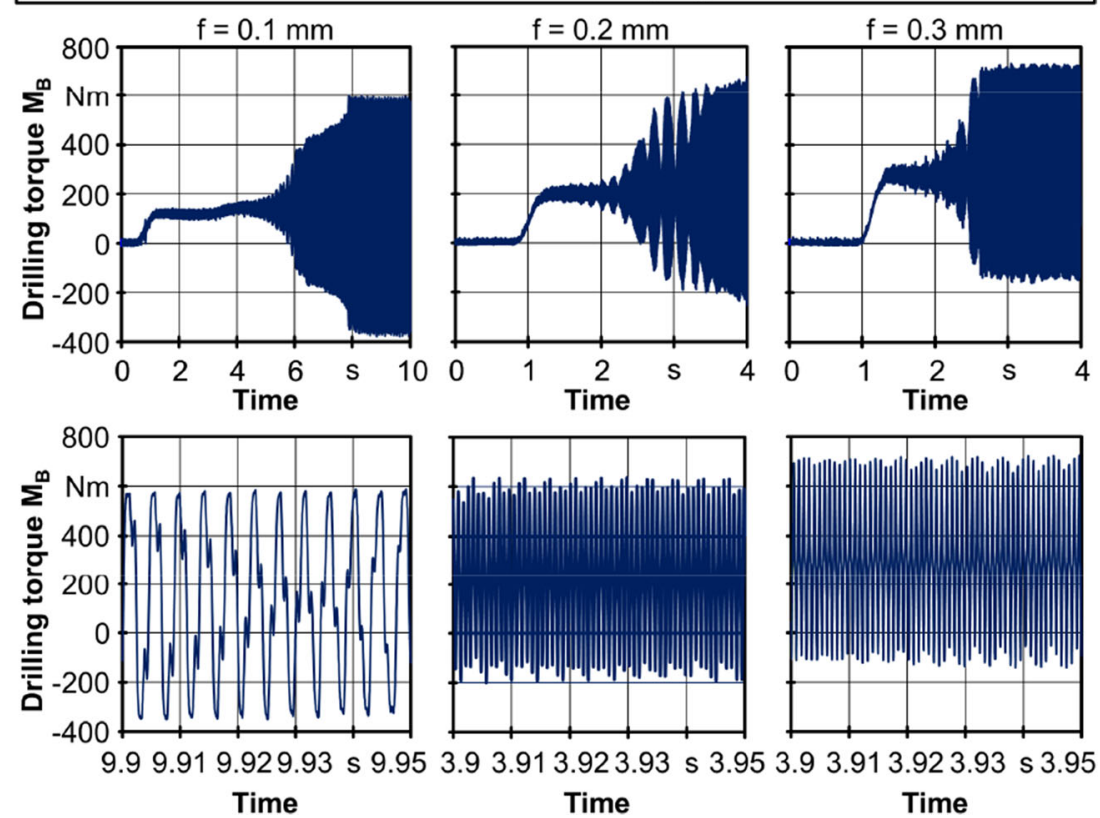

\subsection{Results and discussion}

Machining of AISI 1060 is characterised by reliable chip breaking and high process stability. Thus, the STS deep hole drilling is not accompanied by vibrations of the boring bar when choosing low cutting parameters. Fig. 9 points out the influence of the feed rate on torsional vibrations of the boring bar. These tests were carried out without the use of a lanchester damper of the deep hole drilling machine.

The analysis of the drilling torque shows a stable process without chatter vibrations when using feed rates within $f=0.2$ $\mathrm{mm}$. In contrast, an increased feed rate of $f=0.3 \mathrm{~mm}$ causes intense vibrations of the tool, which can be identified by the oscillation of the drilling torque with $M_{\mathrm{B}} \approx \pm 475 \mathrm{Nm}$.
According to the FFT in Fig. 9, the oscillation of the boring bar is characterised by three frequencies, whereas it can be pointed that the lowest frequency has the largest amplitude.

In contrast to AISI 1060, STS deep hole drilling of the austenitic steel AISI 304 is more challenging. In general, this material tends to long chip formation as well as strong chatter vibrations, already at moderate cutting parameters. Fig. 10 shows the measured drilling torque depending on varying feed rates. Cutting parameters and experimental setup are equal to the previous STS deep hole drilling of AISI 1060 (Fig. 9).

In comparison to the machining of AISI 1060, drilling of AISI 304 initiates strong chatter vibrations even at low feed rates of $f=0.1 \ldots 0.2 \mathrm{~mm}$. Whereas the amplitudes of the vibrations are comparable, the analysed frequencies differ
Fig. 11 Torsional vibrations depending on feed rates when drilling AISI 304 with the CFRPboring bar

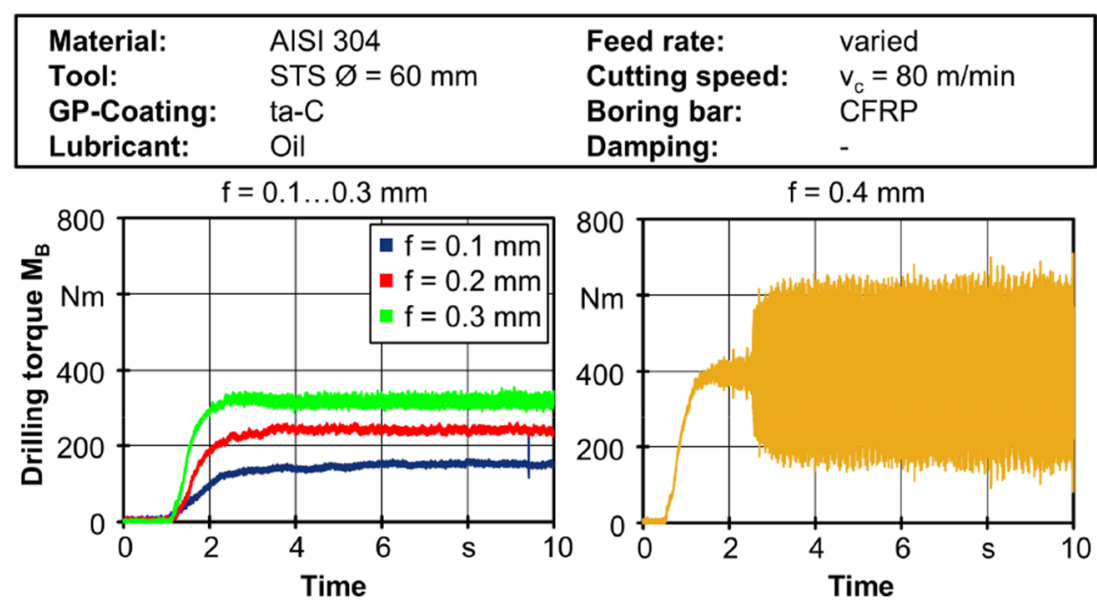


Fig. 12 Measured drilling torques depending on the use of a damping system

\begin{tabular}{|llll|}
\hline Material: & AISI 304 & Feed rate: & $f=0.3 \mathrm{~mm}$ \\
Tool: & STS $\varnothing=60 \mathrm{~mm}$ & Cutting speed: & $\mathrm{V}_{\mathrm{c}}=80 \mathrm{~m} / \mathrm{min}$ \\
GP-Coating: & ta-C & Boring bar: & varied \\
Lubricant: & Oil & Damping: & varied \\
\hline
\end{tabular}
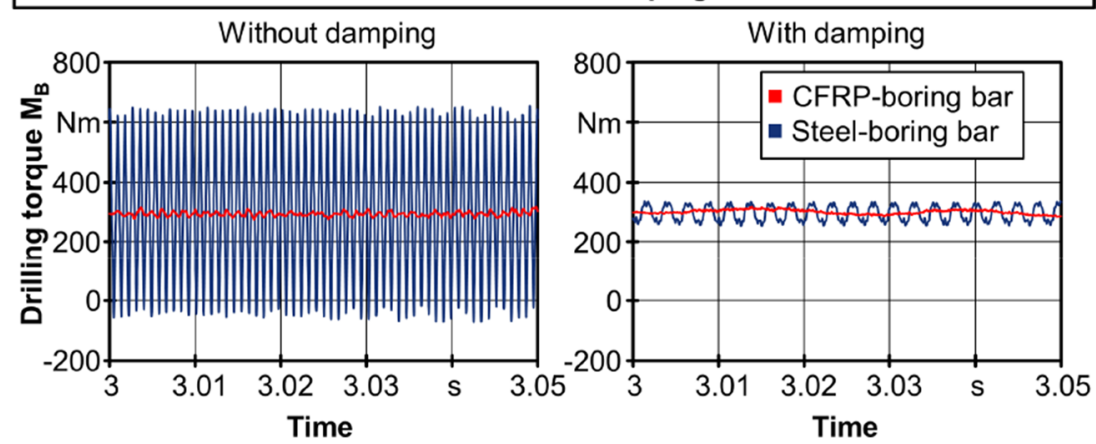

between AISI 304 and AISI 1060. At a feed rate of $f=0.1 \mathrm{~mm}$, vibrations of the boring bar with a lower frequency were obtained. An increase of the feed rate up to $f=0.3 \mathrm{~mm}$ leads to higher chattering frequencies.

A possibility for process stabilisation in STS deep hole drilling of austenitic steel is the application of a damper system, specifically a lanchester damper. The vibration-reducing effect of these systems depends on chattering frequencies as well as the position of the damper. During a deep hole drilling process, these frequencies depend, among other factors, on the chosen cutting parameters and the drilling depth $l_{\mathrm{f}}$. Thus, the position of the damper has to be changed to get an enhanced damping effect.

For these reasons, a self-damping CFRP-boring bar was developed to increase the dynamic process stability separated from drilling depth. The purpose of the development is a stable drilling process with significantly reduced chatter vibrations and constant mechanical tool loads on the cutting edges and guide pads. The innovative boring bar was applied in STS deep hole drilling of AISI 304 with respect to varying feed rates. Fig. 11 shows the measured drilling torques depending on applied feed rates.
At feed rates $f=0.1 \ldots 0.3 \mathrm{~mm}$, the oscillation of the drilling torque is reduced significantly. The self-damping properties of CFRP enable a stable process without the application of an additional damper system [38]. This enables a reduction of the maximum mechanical load on cutting edges and guide pads of the tool. Moreover, the required power output of the machine tool was decreased. Further increase of the feed rate up to $f=$ $0.4 \mathrm{~mm}$ affects torsional vibrations of the boring bar with an amplitude of the drilling torque of $\Delta M_{\mathrm{B}} \approx \pm 250 \mathrm{Nm}$, which is significantly lower compared to the amplitude of the drilling torque when drilling with a conventional steel-boring bar (Fig. 9; $\Delta M_{\mathrm{B}} \approx \pm 400 \ldots \pm 450 \mathrm{Nm}$ ). Consequently, a CFRP-boring bar can help reduce the likelihood of tool failure.

To reduce the amplitude of the torsional vibrations, it is appropriate to use the lanchester damper of the machine tool. When using conventional steel-boring bars, the process reliability and the bore hole quality can be increased using one or more dampers. Fig. 12 compares the amplitudes of the measured drilling torque for both investigated boring bars when drilling austenitic steel.

The effectiveness of the lanchester damper is clearly shown by the reduction of oscillation. To point out the behaviour
Fig. 13 Torsional vibrations with respect to the CFRP-boring bar when machining AISI 304 with a feed rate of $f=0.4 \mathrm{~mm}$ and an activated damping

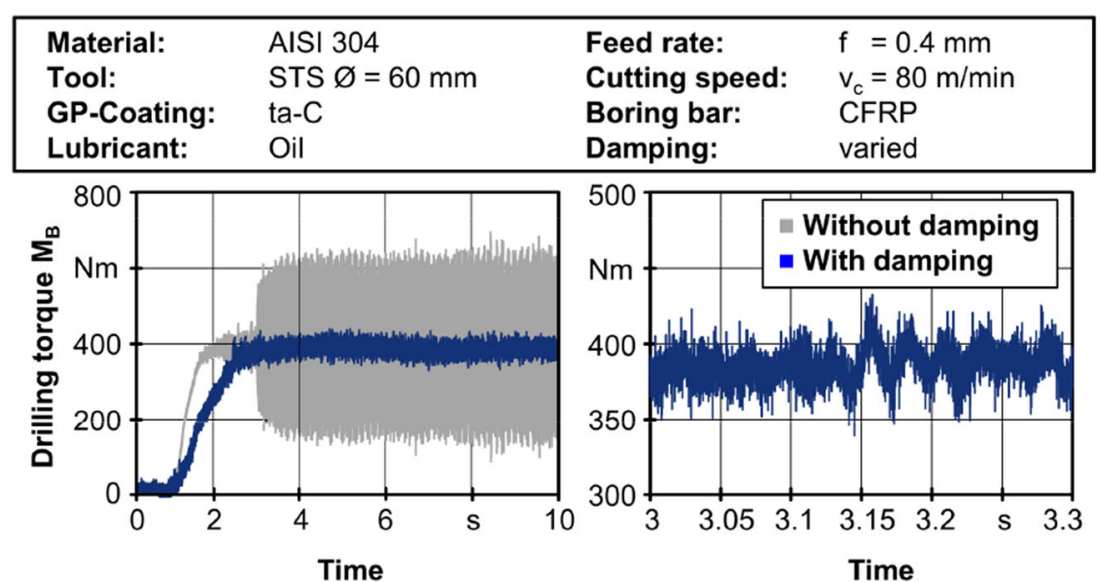


Fig. 14 Comprehensive evaluation of influence of pretreatment and use of cooling lubricant in order to increase bore quality

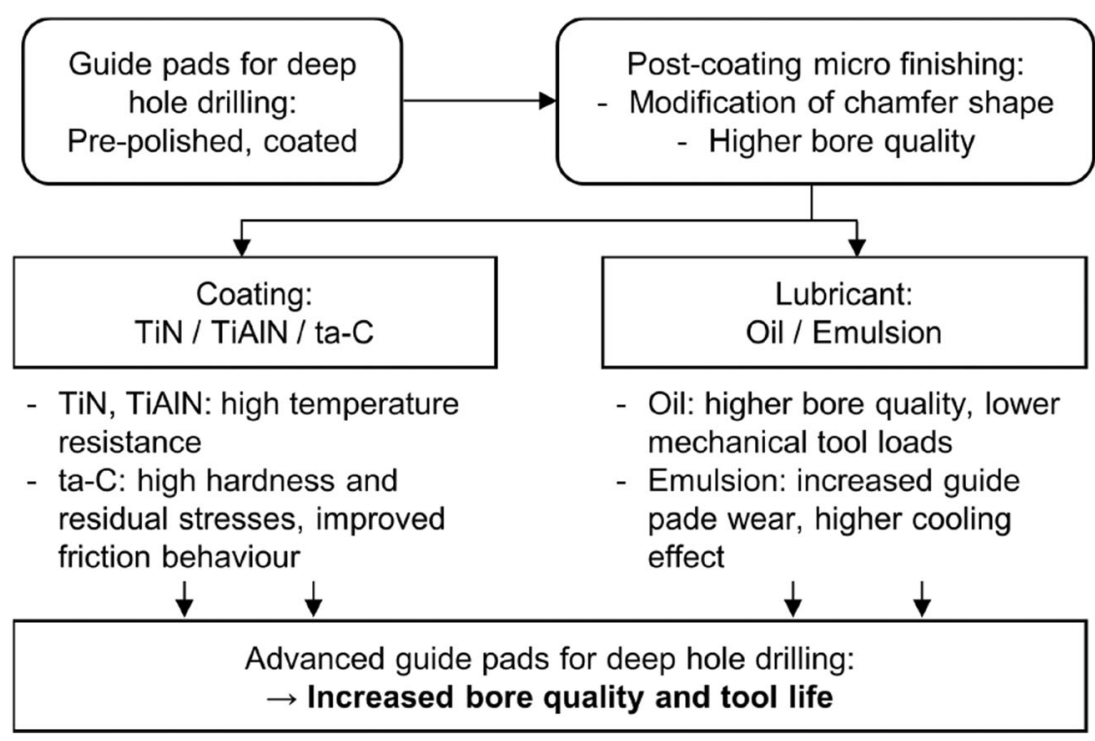

under high mechanical loads, deep hole drilling processes with a feed rate of $f=0.3 \mathrm{~mm}$ were chosen.

The occurring mechanical loads result in strong vibrations of the steel-boring bar whereas the CFRPboring bar oscillates with a significantly smaller amplitude. The damping system enables a reduction of vibrations for both boring bars. It can be pointed out that the range of the drilling torque is about $\Delta M_{\mathrm{B}} \approx \pm 40 \mathrm{Nm}$, when using the steel bar. In comparison, the amplitude when using the CFRP-boring bar is already half as large without the application of an additional damper $\left(\Delta M_{\mathrm{B}}=\right.$ $\pm 20 \mathrm{Nm}$ ). It should be noted that the drilling torque was recorded on the boring bar behind the damper. Consequently, larger amplitudes are likely to occur between the drill head and the damper.
The oscillation of the CFRP-boring bar can also be reduced by activating the damper system. According to Fig. 11 , deep hole drilling with a feed rate of $f=0.4 \mathrm{~mm}$ causes strong chatter vibrations. Therefore, the effectiveness of the damper was analysed for this feed rate. The influence of a damper system on the drilling torque when using a CFRPboring bar is shown in Fig. 13.

The results point out that also when using a CFRPboring bar, the process can be further stabilised by a damper system. The amplitude of the drilling torque is about $\Delta M_{\mathrm{B}} \approx \pm 25 \mathrm{Nm}$, which results in constant mechanical tool loads. This emphasises the potential of the carbon fibre boring bar in order to increase the productivity in machining of austenitic steels by enabling a stable process.
Fig. 15 Comprehensive evaluation damping methods for STS-boring process

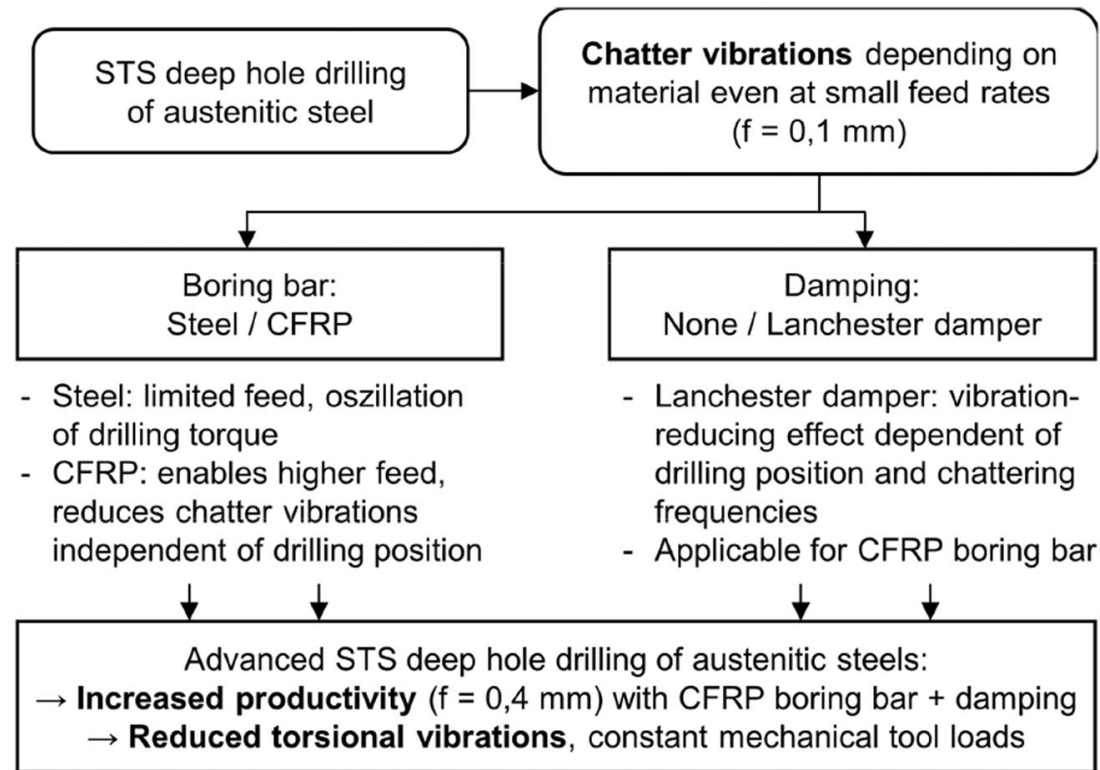




\section{Conclusion}

In experimental tests on deep hole drilling, the influence of tribologically optimised guide pads on the process was analysed. It was shown that the modification of the axial run-in chamfer shape by a micro finishing process can increase the bore quality, independent of coating and lubricant. The results can be applied in particular to the conventional guide pad coatings TiN and TiAlN. The potential of ta-C coating is still limited to deep hole drilling using oil. The lower lubricating effect of an emulsion causes high thermal load on the guide pads, which is particularly challenging with ta-C coating. Uddin et al. established that TiN coatings provide decreased tool wear, while simultaneously lowering surface quality in machining of adhesive aluminium alloys [39]. In general, drilling AISI 304 causes stronger wear on the guide pads using emulsion compared to drilling with oil.

This inevitably leads to lower bore hole quality as well as higher mechanical tool loads. In comparison to more ecofriendly lubrication techniques like MQL, significantly higher surface qualities were occurred [40]. The studies show that to achieve high bore quality and tool life, deep drilling of austenitic steel should be carried out under oil (Fig. 14)

The use of a CFRP-boring bar for STS deep hole drilling has large potential to increase the productivity of industrial deep hole drilling processes. The damping characteristic of CFRP leads to a reduction of chatter vibrations during the drilling process. Especially, the drilling of high alloyed materials typically requires moderate cutting parameter to avoid highly fluctuating mechanical loads on cutting inserts and guide pads. In experimental tests with CFRP-boring bars, more constant drilling torque was measured. This enables the possibility to apply more productive cutting parameters even without the use of an additional damper system. The results are briefly summarised in Fig. 15.

In following research projects, the maximum load on CFRP-boring bars has to be analysed to evaluate the process limits for industrial applications. In order to improve damping qualities, proven effects of structural and technological parameters of CFRP material on machining should be investigated [41]. Moreover, the variation of bore diameter and boring length should be analysed in future tests.

Author contribution NF (experimental investigations, analysis, author); TR (experimental investigations, analysis, author); DB (editor, supervisor), DS (coating analysis, author); WT (editor, supervisor); MF (experimental investigations, analysis, author); HA (experimental investigations, analysis).

Funding Open Access funding enabled and organized by Projekt DEAL. The investigations described in this paper were carried out with the support of the German Research Foundation (DFG) within a special research project 'Entwicklung von tribologisch optimierten Führungsleisten für das Tiefbohren' (Project No. 276395118).

Data availability Not applicable.

Code availability Not applicable.

\section{Declarations}

Conflict of interest The authors declare no competing interests.

Open Access This article is licensed under a Creative Commons Attribution 4.0 International License, which permits use, sharing, adaptation, distribution and reproduction in any medium or format, as long as you give appropriate credit to the original author(s) and the source, provide a link to the Creative Commons licence, and indicate if changes were made. The images or other third party material in this article are included in the article's Creative Commons licence, unless indicated otherwise in a credit line to the material. If material is not included in the article's Creative Commons licence and your intended use is not permitted by statutory regulation or exceeds the permitted use, you will need to obtain permission directly from the copyright holder. To view a copy of this licence, visit http://creativecommons.org/licenses/by/4.0/.

\section{References}

1. Biermann D, Bleicher F, Heisel U, Klocke F, Möhring HC, Shih A (2018) Deep hole drilling. CIRP Annals 67(2):673-694. https://doi. org/10.1016/j.cirp.2018.05.007

2. Fuß H (1986) Aspekte zur Beeinflussung der Qualität beim BTATiefbohren (Aspects influencing quality in BTA deep drilling). University of Dortmund, Dissertation

3. Griffiths BJ, Grieve RJ (1985) The role of the burnishing pads in the mechanics of the deep drilling process. International Journal of Production Research 23(4):647-655. https://doi.org/10.1080/ 00207548508904735

4. Biermann D, Kessler N, Upmeier T, Stucky T (2010) Modified DLC-coated guide pads for BTA deep hole drilling tools. Key Engineering Materials - KEY ENG MAT 438:195-202. https:// doi.org/10.4028/www.scientific.net/KEM.438.195

5. Wittkopp S (2007) Einlippentiefbohren nichtrostender Stähle (Single-lip drilling of austenitic steels). University of Dortmund, Dissertation

6. Biermann D, Abrahams H, Goeke S (2014) Optimization of guide pads for the BTA deep hole drilling of high alloyed steels by microfinishing. Production Engineering 8(1):33-40. https://doi. org/10.1007/s11740-013-0505-Z

7. Biermann D, Abrahams H (2013) Tribological Optimization of the shape and the coating of guide pads for the BTA deep hole drilling process of high-alloyed steels. Paper presented at the STC "C", Paris,

8. Scheibe HJ Mechanical properties of laser-assisted deposited amorphous carbon films. In: 1st International Specialist Meeting on Amorphous Carbon, 1997. pp 252-261

9. Lin TR (2002) Cutting behaviour using variable feed and variable speed when drilling stainless steel with TiN-coated carbide drills. The International Journal of Advanced Manufacturing Technology 19(9):629-636. https://doi.org/10.1007/s001700200106

10. Agapiou J, Stephenson DA (2013) Cutting tool wear and failure mechanisms. In: Wang QJ, Chung Y-W (eds) Encyclopedia of 
tribology. Springer US, Boston, MA, pp 661-677. https://doi.org/ 10.1007/978-0-387-92897-5 605

11. Weinert K, Löbbe H (2003) Einsatzverhalten beschichteter Einlippenbohrer - Tiefbohren von 42CrMo4V mit Emulsion auf Bearbeitungszentren (Application behavior of coated single-lip drills for deep hole drilling 42CrMo4+QT with emulsion on machining centers). Wt Werkstattstechnik 93(H1/2):102-104

12. Hao T, Du J, Su G, Zhang P, Sun Y, Zhang J (2020) Mechanical and cutting performance of cemented carbide tools with $\mathrm{Cr} / \mathrm{x} / \mathrm{DLC}$ composite coatings. The International Journal of Advanced Manufacturing Technology 106(11):5241-5254. https://doi.org/ 10.1007/s00170-020-05014-5

13. Richard C (2013) Tribological coatings for high-temperature applications. In: Wang QJ, Chung Y-W (eds) Encyclopedia of tribology. Springer US, Boston, MA, pp 3778-3787. https://doi.org/10.1007/ 978-0-387-92897-5_1194

14. Lawrance G, Paul S, Varadarajan As, Vasanth X, Raj S (2019) Suppression of tool vibration in boring process: a review. Journal of The Institution of Engineers (India): Series C 100. doi:10.1007/ s40032-019-00531-z

15. Liu X, Liu Q, Wu S, Liu L, Gao H (2017) Research on the performance of damping boring bar with a variable stiffness dynamic vibration absorber. The International Journal of Advanced Manufacturing Technology 89(9):2893-2906. https://doi.org/10. 1007/s00170-016-9612-2

16. Yang S, Tong X, Ma X, Ji W, Liu X, Zhang Y (2018) The guide block structure design of boring and trepanning association (BTA) deep hole drilling. The International Journal of Advanced Manufacturing Technology 99(1):911-918. https://doi.org/10. 1007/s00170-018-2418-7

17. Hussein R, Sadek A, Elbestawi MA, Attia MH (2020) Effect of process parameters on chip formation during vibration-assisted drilling of Ti6Al4V. The International Journal of Advanced Manufacturing Technology 106(3):1105-1119. https://doi.org/10. 1007/s00170-019-04627-9

18. Weinert K, Mehnen J, Webber O, Busse A, Hüsken M, Stagge P (2001) Experimental investigation of the dynamics of the BTA deep hole drilling process. Production Engineering 13(2):1-4

19. Bouzakis K-D, Michailidis N, Skordaris G, Bouzakis E (2019) Coated Tools. In: Chatti S, Laperrière L, Reinhart G, Tolio T (eds) CIRP Encyclopedia of production engineering. Springer, Berlin Heidelberg, Berlin, Heidelberg, pp 275-287. https://doi. org/10.1007/978-3-662-53120-4_6395

20. Li Y, Liu C, Hua J, Gao J, Maropoulos P (2019) A novel method for accurately monitoring and predicting tool wear under varying cutting conditions based on meta-learning. CIRP Annals 68(1):487490. https://doi.org/10.1016/j.cirp.2019.03.010

21. Arif R, Fromentin G, Rossi F, Marcon B (2019) Mechanical analysis of local cutting forces and transient state when drilling of heatresistant austenitic stainless steel. The International Journal of Advanced Manufacturing Technology 104(5):2247-2258. https:// doi.org/10.1007/s00170-019-03969-8

22. Martinho RP, Silva FJG, Martins C, Lopes H (2019) Comparative study of PVD and CVD cutting tools performance in milling of duplex stainless steel. The International Journal of Advanced Manufacturing Technology 102(5):2423-2439. https://doi.org/10. 1007/s00170-019-03351-8

23. Nickel J, Baak N, Biermann D, Walther F (2019) Barkhausen noise-based fatigue life prediction of deep drilled AISI 4140. Procedia Structural Integrity 18:274-279. https://doi.org/10.1016/ j.prostr.2019.08.164

24. Matthews A, Holmberg K (2013) PVD and CVD Coatings. In: Wang QJ, Chung Y-W (eds) Encyclopedia of tribology. Springer US, Boston, MA, pp 2705-2711. https://doi.org/10.1007/978-0387-92897-5 724
25. Bouzakis K-D, Michailidis N (2019) Physical Vapor Deposition (PVD). In: Chatti S, Laperrière L, Reinhart G, Tolio T (eds) CIRP encyclopedia of production engineering. Springer, Berlin Heidelberg, Berlin, Heidelberg, pp 1308-1316. https://doi.org/10. 1007/978-3-662-53120-4 6489

26. Bobzin K (2017) High-performance coatings for cutting tools. CIRP Journal of Manufacturing Science and Technology 18:1-9. https://doi.org/10.1016/j.cirpj.2016.11.004

27. Erdemir A, Donnet C (2006) Tribology of diamond-like carbon films: recent progress and future prospects. Journal of Physics D: Applied Physics 39:R311-R327. https://doi.org/10.1088/00223727/39/18/R01

28. Oliver WC, Pharr GM (1992) An improved technique for determining hardness and elastic modulus using load and displacement sensing indentation experiments. Journal of Materials Research 7(6): 1564-1583. https://doi.org/10.1557/JMR.1992.1564

29. Navarro-Devia JH, Amaya C, Caicedo JC, Martínez JH, Aperador W (2019) Hafnium and vanadium nitride multilayer coatings [HfN/ $\mathrm{VN}] \mathrm{n}$ deposited onto HSS cutting tools for dry turning of a low carbon steel: a tribological compatibility case study. The International Journal of Advanced Manufacturing Technology 101(5):2065-2081. https://doi.org/10.1007/s00170-018-3020-8

30. Uddin GM, Jawad M, Ghufran M, Saleem MW, Raza MA, Rehman ZU, Arafat SM, Irfan M, Waseem B (2019) Experimental investigation of tribo-mechanical and chemical properties of TiN PVD coating on titanium substrate for biomedical implants manufacturing. The International Journal of Advanced Manufacturing Technology 102(5):1391-1404. https://doi.org/10. 1007/s00170-018-03244-2

31. Zhang J (2013) Bonding at surfaces/interfaces. In: Wang QJ, Chung Y-W (eds) Encyclopedia of tribology. Springer US, Boston, MA, pp 247-249. https://doi.org/10.1007/978-0-387-92897-5_453

32. Tillmann W, Stangier D, Hagen L, Schröder P, Krabiell M (2017) Influence of the WC grain size on the properties of $\mathrm{PVD} / \mathrm{HVOF}$ duplex coatings. Surface and Coatings Technology 328:326-334. https://doi.org/10.1016/j.surfcoat.2017.08.064

33. Weinert K, Bruchhaus T (1999) Tribological investigations into the operational behavior of self-piloting drilling tools. Wear 225-229: 925-935. https://doi.org/10.1016/S0043-1648(98)00411-6

34. Budak E (2019) Chatter. In: Chatti S, Laperrière L, Reinhart G, Tolio T (eds) CIRP encyclopedia of production engineering. Springer, Berlin Heidelberg, Berlin, Heidelberg, pp 226-231. https://doi.org/10.1007/978-3-662-53120-4_6523

35. Korkut I, Kasap M, Ciftci I, Seker U (2004) Determination of optimum cutting parameters during machining of AISI 304 austenitic stainless steel. Materials \& Design 25(4):303-305. https://doi.org/ 10.1016/j.matdes.2003.10.011

36. Nayak SK, Patro JK, Dewangan S, Gangopadhyay S (2014) Multiobjective optimization of machining parameters during dry turning of AISI 304 austenitic stainless steel using grey relational analysis. Procedia Materials Science 6:701-708. https://doi.org/10.1016/j. mspro.2014.07.086

37. Sun Y, Rana V (2011) Tribocorrosion behaviour of AISI 304 stainless steel in $0.5 \mathrm{M} \mathrm{NaCl}$ solution. Materials Chemistry and Physics 129(1):138-147. https://doi.org/10.1016/j.matchemphys.2011.03. 063

38. Treviso A, Van Genechten B, Mundo D, Tournour M (2015) Damping in composite materials: properties and models. Composites Part B: Engineering 78:144-152. https://doi.org/10. 1016/j.compositesb.2015.03.081

39. Uddin GM, Joyia FM, Ghufran M, Khan SA, Raza MA, Faisal M, Arafat SM, Zubair SWH, Jawad M, Zafar MQ, Irfan M, Waseem B, Chaudhry IA, Zeid I (2021) Comparative performance analysis of cemented carbide, TiN, TiAlN, and PCD coated inserts in dry machining of Al 2024 alloy. The International Journal of Advanced 
Manufacturing Technology 112(5):1461-1481. https://doi.org/10. 1007/s00170-020-06315-5

40. Sultan AZ, Sharif S, Nor FM, Kurniawan D (2019) Minimum quantity of lubricant drilling of stainless steel using refined palm olein: effect of coating tool on surface roughness and tool wear. Procedia Manufacturing 30:427-434. https://doi.org/10.1016/j. promfg.2019.02.059
41. Ghorbani S, Rogov VA, Carluccio A, Belov PS (2019) The effect of composite boring bars on vibration in machining process. The International Journal of Advanced Manufacturing Technology 105(1):1157-1174. https://doi.org/10.1007/s00170-019-04298-6

Publisher's note Springer Nature remains neutral with regard to jurisdictional claims in published maps and institutional affiliations. 